\title{
Ressignificando uma prática pedagógica de alfabetização: um novo olhar sob a égide das novas Tecnologias Digitais
}

\author{
Cristina Ferreira Branco (MPNTDE | UniCarioca |Colédio Pedro II) \\ Gilsely de C. G. do Nascimento (MPNTDE |UniCarioca|Colédio Pedro II) \\ Renatho Siqueira (MPNTDE | UniCarioca) \\ André Cotelli E. Santo (NUCAP | MPNTDE | UniCarioca)
}

\section{Resumo}

Este artigo se propõe a apresentar uma prática pedagógica aplicada no $1^{\circ}$ ano do ensino fundamental em uma escola pública da esfera federal, estando pautada nos estudos de Ferreiro e Teberosky (1986) sobre a psicogênese da língua escrita, relacionando-os aos conceitos de letramento definidos por Soares (2005) e resgatando as técnicas usadas por Paulo Freire na sua proposta de alfabetização, implantada entre adultos na década de 60. Essa prática trabalha com o conceito das palavras geradoras (Freire, 1967) advindas do universo do aluno, o que torna o processo de construção da escrita significativo, dinâmico e prazeroso. Propõe ainda apresentar a ressignificação dessa prática com o objetivo de atender às demandas de uma geração que já nasce conectada, a chamada geração Z, que chega à escola, exigindo uma nova perspectiva para o processo de ensino e aprendizagem. Busca-se transplantar o referido trabalho para o universo das novas tecnologias a partir da utilização de ferramentas digitais que trarão uma nova perspectiva em sua abordagem do mesmo, promovendo uma interação maior entre as famílias diante das telas do computador, tablet e celular, tornando esses dispositivos móveis importantes aliados na construção do conhecimento.

Palavras- chave: alfabetização; letramento; ressignificação; novas tecnologias.

\begin{abstract}
This article proposes to present a pedagogical practice applied in the first year of elementary school in a public school of the federal sphere, being based on the studies of Ferreiro and Teberosky (1986) on the psychogenesis of written language, relating them to defined concepts of literacy by Soares (2005) and rescuing the techniques used by Paulo Freire in his proposal of literacy, implanted among adults in the 60's. This practice works with the concept of generating words (Freire, 1967) that explore the universe of the student, which makes the writing process meaningful, dynamic and enjoyable. It also intends to present the re-signification of this practice in order to meet the demands of a generation that is already born connected, the so-called generation $Z$, who arrives at school, demanding a new perspective for the teaching and learning process. This work seeks to transplant the work to the universe of new technologies using digital tools that will bring a new perspective in the approach of the same, promoting a greater interaction between the families before the screens of the computer, tablet and cellular, making these devices important allies in the construction of knowledge.
\end{abstract}

Keywords: literacy, resignification, new technologies.

\section{Introdução}

Este artigo tem por objetivo apresentar a ressignificação de uma prática pedagógica, identificando e apontando oportunidades de aprimoramento desta experiência conforme os conhecimentos e competências produzidos na disciplina.

Considerando que o conceito "prática educativa" abriga qualquer tipo de artefato ou experiência em que sujeitos praticantes constroem conhecimentos, o recorte deste trabalho recai sobre uma prática presente na educação formal, mais precisamente no $1^{\circ}$ ano do ensino fundamental do Colégio Pedro II, Campus Tijuca I.

Trata-se de uma sequência didática utilizada nas classes de alfabetização: a construção de textos coletivos mediados pelo professor, sendo muito utilizada, desde os primeiros dias de aula, objetivando levar os alunos a refletirem sobre a estrutura textual, a organização de ideias no texto, a forma e utilização dos diversos gêneros textuais. 
A estratégia selecionada ganha um enforque diferente à medida que fomenta a construção de textos diferentes a partir da discussão surgida em cada turma de $1^{\circ}$ ano e se constitui no ponto de partida para o trabalho de um período letivo. Desses textos surgirão vários projetos e deles serão retiradas as palavras de referência utilizadas nas atividades de alfabetização.

Num segundo momento, o artigo proporá uma ressignificação da prática sob a égide das novas tecnologias digitais, buscando atender a uma demanda do mundo atual que vive os efeitos da chamada Revolução Tecnológica, trazendo como foco o advento das novas tecnologias que encurtam as distâncias e o tempo, propiciando um modus vivendi dinâmico e o imediatismo na apreensão de conhecimentos e informações.

Nesse contexto, está surgindo uma nova geração, denominada geração Z, que, desde muito cedo, está conectada às novas tecnologias que lhe são disponibilizadas, lançando mão delas de forma efetiva.

Os membros dessa geração, que o filósofo francês Michel Serres (2013) denominou, carinhosamente, de "Polegarzinha e Polegarzinho", "habitam o virtual". Assim sendo

Por celular, têm acesso a todas as pessoas; por GPS, a todos os lugares; pela internet, intern , a todo o saber: circulam, então, por um espaço topológico de aproximações" (Serres, 2013, p.19).

Para Serres (2013), essa juventude não vive mais na companhia de animais, "nunca viu um bezerro, uma vaca, um porco, uma ninhada" (p.13), são formatados pela mídia "que há muito tempo assumiu a função do ensino”, ofuscando a escola, pelo “tempo de exposição de que dispõe, pelo poder de sedução e pela importância que tem” (p.19).

Segundo o autor, as ciências cognitivas mostram que o uso das novas tecnologias digitais não ativa os mesmos neurônios nem as mesmas zonas corticais que o uso do livro, do quadro-negro ou do caderno ativou nas gerações anteriores.

É nesse mundo contemporâneo que está inserida a escola como uma microcélula da sociedade e a serviço dessa nova geração. Em função disso, a cada dia, a escola precisa se reinventar, para se inserir nesse "admirável mundo novo", atendendo às suas demandas, instrumentalizando indivíduos para encontrarem seu lugar nesse contexto.

Para isso, se faz necessário que a escola utilize as novas tecnologias que estão incorporadas ao dia-a-dia das sociedades, tornando-as ferramentas para uma aprendizagem mais dinâmica e significativa para essa geração em total conectividade com o mundo a sua volta, estabelecendo novas formas de se comunicar, através de novas linguagens, símbolos que aceleram a comunicação e a transmissão de conhecimento e informação, gerando mudanças de hábitos, comportamentos e valores que acabam exigindo mudanças no âmbito da escola.

Dentro desse contexto, o processo de aprendizagem da leitura e da escrita ganhou uma nova dimensão e, em função disso, as tradicionais metodologias de alfabetização não conseguem atender às demandas que têm chegado à escola com as novas gerações. Destarte se faz necessária a incorporação de ferramentas tecnológicas de forma a promover uma aprendizagem lúdica e significativa, na qual o aluno seja protagonista de seu processo de aprendizagem, apropriando-se da leitura e da escrita ativamente, como exigem os novos tempos.

\section{Desenvolvimento}

\section{Fundamentação teórico-metodológica}

A análise da estratégia selecionada como objeto deste trabalho requer a contextualização temporal e teórica.

Primeiramente, cabe esclarecer que essa estratégia foi introduzida e aprimorada no decorrer de mais de dez anos de experiência de um grupo de professores de uma escola pública federal. Esses professores aliaram teoria às práticas cotidianas e, com base em ambas, foram inserindo modificações, paulatinamente, até chegarem à atual prática.

A primeira pergunta da qual o grupo de professores se ocupou foi: como a criança aprende a linguagem escrita?

Buscando respostas, o grupo se pautou nos estudos de Ferreiro e Teberosky (1986) sobre a psicogênese da língua escrita, que afirmam que a criança constrói hipóteses sobre a escrita muito antes de chegar à escola, desde que entra em contato com portadores de texto em diferentes situações cotidianas.

Desde o primeiro contato, a criança busca compreender o que é a escrita e como funciona, construindo hipóteses baseadas 
nas análises e na experimentação de modos de ler e de escrever, no contato ou na intervenção direta de adultos.

Essas hipóteses vão sendo elaboradas e reelaboradas à medida que o contato e as reflexões sobre esse tipo de tecnologia se ampliam, incorporando as diferentes dimensões desse objeto.

O grupo adotou também o conceito de alfabetização definido por Soares (2005) como "o aprendizado de uma tecnologia de representação da linguagem humana, a escrita alfabético-ortográfica”. Segundo a autora, isso envolve um conjunto de conhecimentos e procedimentos relacionados tanto ao funcionamento desse sistema de representação quanto às capacidades motoras e cognitivas para manipular os instrumentos e equipamentos de escrita:

Conhecimentos e procedimentos: a escrita alfabético-ortográfica é um sistema de representação; ele se distingue de outros sistemas de representação, como o desenho; ele representa certas propriedades do signo linguístico; sua utilização envolve uma automatização das relações entre o escrito e aquilo que representa.

Capacidades motoras e cognitivas: habilidades de ler e escrever seguindo a direção correta da escrita na página, habilidades de uso de instrumentos de escrita (lápis, caneta, borracha, corretivo, régua...), aprendizagem de uma postura corporal adequada na leitura e na escrita, aprendizagem da caligrafia... (Soares, 2005, p.25)

Assim sendo, o processo de alfabetização é complexo e exige atividades didático-pedagógicas que desenvolvam todas essas capacidades e conhecimentos apresentados por Soares (2005).

Atualmente, porém, ser alfabetizado não atende às necessidades sociais e políticas vigentes. Antes, é fundamental saber utilizar a linguagem escrita para exercer uma prática social em que essa modalidade da língua é necessária.

Em outras palavras, o acesso ao mundo da escrita exige habilidades para além do apenas aprender a ler e a escrever, dando origem ao conceito de letramento, que incorpora habilidades de uso da leitura e da escrita desenvolvidas durante alguns anos de escolarização.

O conceito letramento designa, então, "o conjunto de conhecimentos, atitudes e capacidades envolvidos no uso da língua em práticas sociais e necessários para uma participação ativa e competente na cultura escrita” (Soares, 2005, p. 50).

Uma pessoa pode ser alfabetizada e não ser letrada: saber ler e escrever, mas não cultivar nem exercer práticas de leitura e de escrita, não ler livros, jornais, revistas, ou não ser capaz de interpretar um texto lido; ter dificuldades para escrever uma carta ou um bilhete.

Ao mesmo tempo,

Uma criança pode ainda não ser alfabetizada, mas ser letrada: uma criança que vive num contexto de letramento, que convive com livros, que ouve histórias lidas por adultos, que vê adultos lendo e escrevendo, cultiva e exerce práticas de leitura e de escrita, toma o livro e finge que está lendo (e aqui de novo é interessante observar que, quando finge ler, usa as convenções e estruturas linguísticas próprias da narrativa escrita), toma papel e lápis e "escreve" uma carta, uma história. Ainda não aprendeu a ler e escrever, mas é, de certa forma, letrada, tem já um certo nível de letramento. (Soares, 2005, p.51).

Cabe esclarecer que alfabetização e letramento não ocorrem isoladamente. São interdependentes e indissociáveis: "a alfabetização desenvolve-se no contexto de e por meio de práticas sociais de leitura e de escrita, isto é, através de atividades de letramento, e este, por sua vez, só se pode desenvolver no contexto da e por meio da aprendizagem das relações fonemagrafema, isto é, em dependência da alfabetização" (Soares, 2000, p.14-15).

Considerando toda a complexidade que envolve a alfabetização de crianças de seis anos de idade, o grupo recorreu também ao método Paulo Freire, realizando adaptações ao mundo infantil.

Assim sendo, procuraram evitar "doar ao analfabeto palavras e sentenças que, realmente, devem resultar do seu esforço criador" (Freire, 1967, p.111) e buscaram, nas conversas iniciais com os alunos, levantar o universo vocabular deles, bem como as possíveis necessidades de intervenção pedagógica.

Com base nesses pressupostos, os professores de Núcleo Comum (Língua Portuguesa, Estudos Sociais, Matemática e Ciências) queatuam no $1^{\circ}$ ano do Ensino Fundamental uniram-se à coordenação de Artes e, da discussão de propostas voltadas para a alfabetização, surgiu a ideia da criação de uma história imagética que promovesse a seleção de palavras de referência (palavras geradoras de Freire), bem como dos assuntos a serem abordados pelo grupo.

A professora de Artes construiu a história imagética que foi utilizada para uma produção de um texto coletivo, tendo a professora de cada turma como mediadora e escriba. Por ser um texto autoral, ganha grande significado para os alunos, 
pois cada um constrói um final individual para a história, produzindo um livro com aquela história.

As palavras de referência foram retiradas do texto coletivo levando-se em consideração a riqueza fonêmica. Posteriormente, foram decompostas em seus elementos silábicos propiciando, pela combinação dessas sílabas, a criação de novas palavras, conforme preconizava o método Paulo Freire. Posteriormente, é feita a substituição das vogais, dando origem à família silábica e à composição de novas palavras.

\section{Metodologia}

A metodologia adotada na implementação da prática pedagógica se constrói em etapas que serão apresentadas a seguir, tendo como ponto de partida a escolha da temática que norteia a construção da história imagética que dará suporte ao trabalho. Estando esta concretizada, propõe-se uma sequência didática integrando atividades e conceitos de diferentes áreas do conhecimento, e voltada para à aprendizagem da leitura e da escrita de forma significativa, tendo em vista faixa etária em que estão os alunos.

Nessa sequência, a tecnologia se insere para tornar o processo mais dinâmico, ultrapassando o espaço físico da sala de aula e integrando e aproximando a família do aluno nessa caminhada pelo mundo das letras, palavras e sentenças, numa parceria necessária ao processo ensino-aprendizagem.

\section{Breve relato sobre a sequência didática desenvolvida: uso de história imagética como base para a construção de textos de autoria coletiva para a alfabetização}

A sequência didática escolhida como base para este artigo surge a partir de várias etapas, todas igualmente necessárias para a construção de um trabalho significativo e que torne o aluno protagonista dentro do processo de alfabetização.

Inicialmente se faz necessário um conhecimento desses alunos que chegam ao $1^{\circ}$ ano, através de sorteio público, e por isso oriundos dos mais diferentes contextos geográficos e socioeconômicos. Para isso, durante as rodas de conversa promovidas na turma, os professores fazem um levantamento, informalmente, das preferências dos alunos (brincadeiras, animais, programas de TV, comida, o que gosta de fazer, jogos, pessoas, etc.). Esse levantamento se traduz em gráficos e tabelas construídos coletivamente e afixados na sala de aula.

Paralelamente, vários conceitos relativos à alfabetização estão sendo trabalhados, usando-se, para tanto, os nomes das crianças, através da comparação entre eles (quantidades de letras, letras comuns, sonoridade dessas letras). Nessa fase também é apresentado o alfabeto, e as vogais são destacadas para que o valor sonoro delas seja atribuído.

Com base nas preferências das crianças, seus anseios, nas discussões surgidas nas rodas diárias de conversas e nos objetivos a serem desenvolvidos, o grupo de professores se reúne para traçar estratégias e o texto inicial (coletivo) do qual se retirarão as palavras geradoras.

As ideias surgidas para o texto inicial são transformadas em uma história imagética composta por uma sequência de ilustrações que é reproduzida e apresentada para as turmas que constroem um texto coletivo para ela, ressaltando-se que em cada turma surge um texto diferente, produto da discussão coletiva.

A história selecionada para este artigo foi construída em 2014, dentro de um contexto que envolveu a Copa do Mundo de Futebol, evento esportivo que reúne pessoas do mundo inteiro - atletas, jornalistas, torcedores - e que esteve presente em várias capitais do Brasil nesse ano. Por ser um assunto que pautou várias conversas, surgiu a ideia de se criar uma história que levasse as crianças a um passeio por alguns lugares da cidade do Rio de Janeiro repletos de significado histórico-cultural, sob a ótica de um personagem nada convencional: um gato preto que foge de casa para dar um passeio pela cidade, conduzindo as crianças nessa breve viagem.

O texto abaixo foi criado por uma turma de $1^{\circ}$ ano, a partir da história imagética que está sendo objeto de análise. 


\section{As aventuras de Romeu}

Romeu era um gato muito fujão, pois ele adorava fugir de casa para passear e tomar um ar puro.

Numa dessas fugidas, Romeu resolveu conhecer melhor a cidade do Rio de Janeiro e passou por vários lugares legais.

Ele passou pelo Pão de Açúcar e andou no calçadão de Copacabana e viu a estátua de um poeta.

Quando já estava anoitecendo Romeu resolveu voltar para casa, mas antes passou em frente a uma favela e viu uma linda Lua brilhante no céu.

Continuou o seu caminho e conheceu a Julieta, uma gatinha muito famosa que vivia pelas ruas da Lapa.

Os dois se apaixonaram e a Julieta foi morar com Romeu.

Figura 1: Texto coletivo produzido pela turma 103/2014 com apoio da história imagética.

Após a criação da história coletiva, há espaço para uma parte individual de criação. Cada figura da história imagética é reproduzida (apenas com o contorno) formando um livro no qual o aluno acrescenta o final da sua história (com texto e ilustração).

\section{FINAL CRIADO POR UM ALUNO}

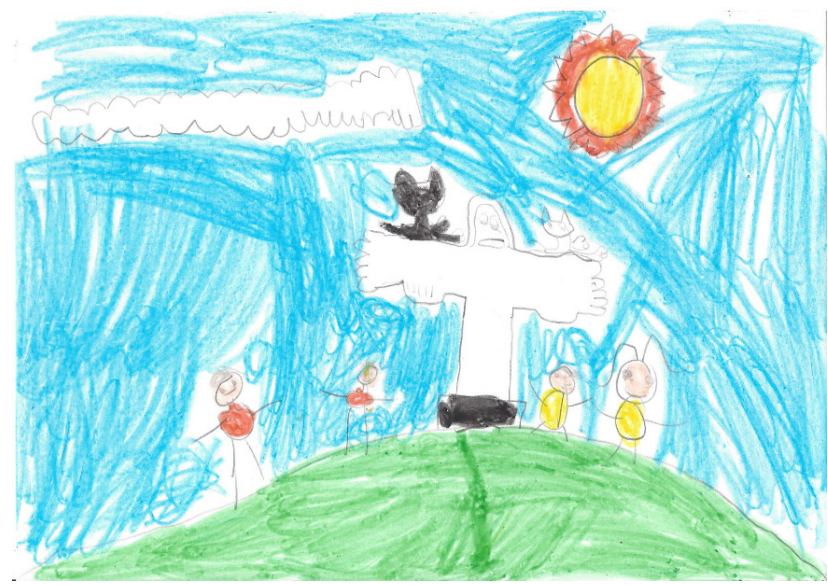

No outro dia eles estavam em casa e fugiram novamente, só que eles não foram para Copacabana, foram para o Cristo Redentor e subiram nos braços do Cristo, de lá viram o Rio de Janeiro todo!

Figura 2: Ilustração e final da história criados por um aluno da turma 101. 
A partir da história coletiva, surgem as palavras geradoras ou palavras de referência que, no caso dessa história, foram: GATO/A, COPACABANA, LUA, FAVELA, POETA e, com elas, formaram-se as famílias silábicas - canônicas, utilizando os fonemas consonantais $(\mathrm{G}, \mathrm{T}, \mathrm{C}, \mathrm{P}, \mathrm{B}, \mathrm{N}, \mathrm{L}, \mathrm{F}, \mathrm{V})$ unidos às vogais (A, E, I, O, U).

Dessa sequência inicial em que se constrói a história, parte-se para vários desdobramentos para além da alfabetização. Utilizaram-se as cores dos gatos visando discutir questões ligadas ao preconceito racial de forma lúdica e leve. Também foram discutidas questões relacionadas ao espaço das favelas, dando protagonismo aos alunos inseridos nesse contexto. Com base na palavra "favela", foi feita a análise das sílabas canônicas com as consoantes F, V e L, e , também se discutiu o que ela significa e o que tem de bom nesses lugares, na tentativa de trazer questões relativas ao dia a dia da cidade para a discussão e desconstrução de pré-conceitos e preconceitos.

Após a construção da história, os alunos do $1^{\circ}$ ano participaram de uma aula de campo, na qual puderam passear pelos lugares por onde o protagonista passou. Essa aula se desdobrou em um trabalho com o mapa da cidade onde os alunos assinalaram os bairros por onde passaram durante o passeio. Por fim, fizeram um relatório coletivo e ilustrado sobre o evento.

Os alunos pesquisaram, no Laboratório de Informática, informações sobre os pontos turísticos visitados e, utilizando técnicas de recorte e colagem, reconstruíram os Arcos da Lapa, o calçadão da Praia de Copacabana e o Pão de Açúcar.

Além disso, também no Laboratório de Informática, pesquisaram sobre Carlos Drummond de Andrade e leram poemas do autor voltados para o público infantil. Continuando o trabalho com diferentes gêneros textuais, leram textos informativos sobre os gatos, já que, em Ciências, estavam estudando os mamíferos, além de poesias e músicas que trouxeram o animal como protagonista.

\section{Dando início ao processo de ressignificação da prática pedagógica}

\section{Conhecendo os sujeitos envolvidos na sequência didática através do Mapa de Empatia}

Os sujeitos praticantes ou personas envolvidos nessa prática são alunos do $1^{\circ}$ ano do Ensino Fundamental de uma escola pública federal, na faixa etária entre seis e sete anos, tendo ingressado nessa escola, através de sorteio público. Esses alunos são, em grande parte, oriundos de bairros como Tijuca, Maracanã, Andaraí e Vila Isabel, entre outros.

Os alunos, em sua maioria, não estão alfabetizados e, por isso, a prática escolhida está voltada para um público de sujeitos praticantes (ALVES, 2015) que não dominam o código escrito, com um universo de leitura pautado em textos não verbais. São leitores de símbolos, sinais, imagens, cores e outros elementos visuais que abrem espaço para a polissemia que marca esse tipo de linguagem.

Esses alunos foram entrevistados a fim de que se soubesse um pouco mais sobre medos, anseios e, preocupações que fazem parte do cotidiano deles, para que, a partir da construção de um Mapa de Empatia, se buscasse a ressignificação da prática apresentada dentro da perspectiva das novas tecnologias digitais.

\section{Aplicando o Mapa de Empatia}

O Mapa de Empatia foi construído a partir de entrevistas feitas com alunos do $1^{\circ}$ ano durante os horários de entrada, recreio e saída. Foram entrevistadas seis crianças na faixa etária de seis anos. As respostas dadas foram registradas nessa ferramenta e, a partir da análise delas, obteve-se um caminho para a ressignificação da prática escolhida. 


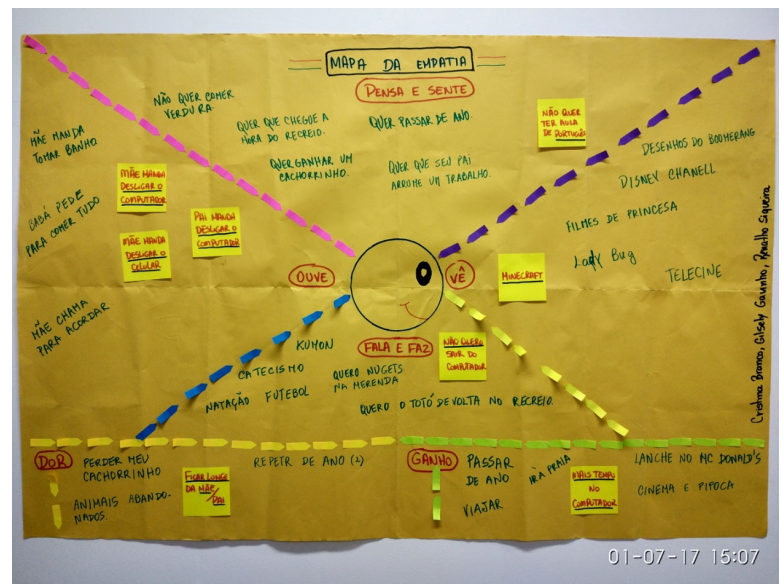

Figura 3: Mapa de empatia criado a partir de conversas informais com alunos do $1^{\circ}$ ano.

A análise do Mapa da Empatia, construído a partir das respostas dadas pelos alunos entrevistados, apontou para algumas ideias que foram destacadas em "post-its" e que nortearam a prática de ressignificação. São elas:

- PENSA E SENTE: Não quer ter aula de português.

- OUVE: Mãe mandando desligar o computador e o celular, igual ao pai.

- VÊ: Minecraft (jogo de computador).

- FALA E FAZ: Não quer sair do computador.

- DOR: Ficar longe da Mãe/Pai.

- GANHO: Mais tempo no computador.

Com base nessas informações, percebeu-se a convergência em relação ao uso das tecnologias na vida dessas crianças, bem como a resistência dos pais ao uso desmedido (ou abusivo) em relação a elas, que se traduz pela regulação do tempo de uso desta ferramenta. Chamou a atenção ainda o fato de que um dos principais temores das crianças é a ausência dos pais e há uma manifesta falta de interesse na língua portuguesa, por não haver um claro senso de propósito, ou aparente "aplicação prática" do que aprendem.

Sendo assim, decidiu-se que a ressignificação proposta deveria ser capaz de trabalhar estes aspectos de forma integrada, dando oportunidade à criança de aprender através do uso de novas tecnologias, utilizando um método que já é comprovadamente funcional, mas fazendo com que seus pais participem do processo, percebendo que o computador e o celular também podem ser usados como ferramentas de educação, e que eles podem - e devem - participar das atividades escolares e pedagógicas dos seus filhos.

A proposta trazida busca ser capaz de resolver essa questão, de forma que o produto final seja atraente para as crianças, permita que eles interajam mais com seus pais, fazendo com que eles estejam mais presentes e ativos na educação dos filhos, usando a tecnologia e compreendendo que, desde que bem utilizados, os artefatos tecnológicos são excelentes fontes de aprendizado e conhecimento. 


\section{Ressignificando a prática através das novas tecnologias digitais: a transformação do ana- lógico no digital}

De posse de todas as informações sobre o que era, de fato, relevante para nosso público-alvo, surgiu a ideia de acrescentar uma nova etapa à sequência didática já desenvolvida, incorporando diversos recursos tecnológicos para criar uma versão digital da história imagética criada.

Em primeiro lugar, a proposta requer que sejam utilizadas cartas ilustradas, ao invés de desenhos em folhas simples, como já é feito. Estas cartas, semelhantes a cartas de baralho, recebem um QRCode (sistema de integração gráfica entre publicações off-line e links de internet) que permite que, posteriormente, sejam "lidas" pelas professoras e enviadas a uma plataforma online que permitirá, em um segundo momento, a participação dos pais na atividade escolar de criação de histórias juntamente com seus filhos.

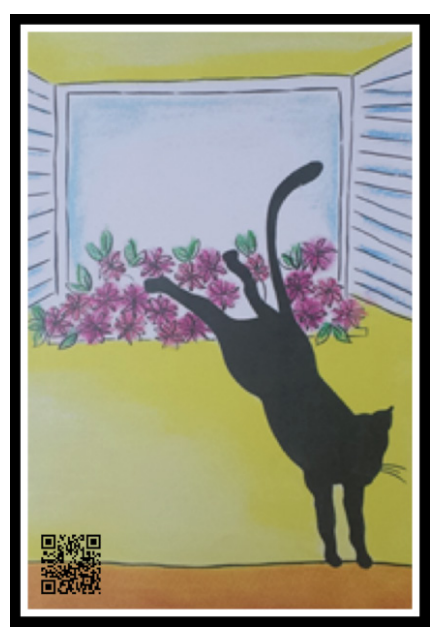

Figura 4: Uma das cenas da história imagética, convertida em carta que recebeu um qRCode.

Com o uso desse recurso, a história deixa de ser linear, abrindo diversas possibilidades de construção, numa estrutura criada para parecer com as antigas séries de livros-jogos Aventuras Fantásticas, de Ian Livingstone e Steve Jackson, assim como com os livros da série Escolha sua Aventura: cada carta leva as crianças a duas ou três possíveis escolhas, de forma que eles possam, durante a aula, construir uma narrativa própria, dando um destino aos personagens.

Este destino será diferente a cada turma, aluno ou aula. Com isso, mesmo utilizando os mesmos personagens e as mesmas cartas, somos capazes de criar dezenas de histórias diferentes a serem trabalhadas com os alunos, aumentando exponencialmente a capacidade de aprimorar a escrita.

Dentro da perspectiva oferecida por essa nova dinâmica, os professores poderiam explorar de forma ainda mais rica e completa a proposta pedagógica da atividade, reforçando ainda mais o vocabulário utilizado e dando oportunidade aos alunos de participarem ainda mais ativamente do processo de "contação" da história.

Após a construção da história, o professor, de posse de um smartphone e, através do acesso à internet e de um aplicativo criado com esta finalidade, lê os códigos nas cartas. Este aplicativo irá fazer com que numa determinada plataforma, criada para ser a versão "eletrônica" da história construída em sala de aula, cada uma das cartas, seguida do seu fragmento de história, seja exibida mediante um sistema simples de controle de acesso, que pode ser a matrícula do aluno, por exemplo. O acesso ao sistema se dará por um link simplificado que será enviado aos pais do aluno através da agenda do aluno.

Nesta plataforma, o aluno, junto com seus pais, poderá - em sua casa - rever a história e pedir para que seus pais a recontem. Os pais perceberão que esta prática educativa, que se apropria da Educação Mediada por Computador, é um recurso pedagógico que permite um uso adequado e responsável da tecnologia para fins educacionais. Com isso, iremos permitir que as crianças passem mais tempo com seus pais, de modo que estes tomem parte na formação escolar de seus filhos. 
Após ler a história para as crianças, os pais serão orientados a pedir que seus filhos façam um desenho livre, à mão, que ilustre o final da história contada a eles. Estes desenhos deverão ser fotografados pelos pais e enviados para a plataforma, onde farão parte da história. Após o envio desta foto do desenho criado pelas crianças, os pais devem exercer o papel de escribas e escrever o final da história contada por seus filhos.

Ao escreverem este texto, todas as palavras geradoras, que fazem parte do planejamento pedagógico daquela atividade, irão emitir sons à medida que forem escritas pelos pais. Dessa forma, geramos um reforço senso-cognitivo que fará com que a criança fique mais atenta à atividade e busque explorar a história de forma mais rica, em busca de outras palavras que também emitam som.

Com essa mudança na aplicação da prática pedagógica, acreditamos que será possível entregar aos alunos um produto final que seja capaz de abranger os principais pontos de interesse destacados no mapa da empatia e, dessa forma, entregar um produto final que seja desejável pelo aluno, despertando neles o interesse em interagir com a plataforma e que seja uma ferramenta que permita que seus pais invistam um tempo na realização de uma atividade prática, mediada por computador, de interesse dos alunos e que amplie as percepções destes pais para as inúmeras possibilidades que os novos artefatos tecnológicos empregados na educação podem trazer.

\section{Considerações finais}

A estratégia de aprendizagem utilizada traz possibilidades múltiplas de trabalho envolvendo ideias relacionadas a diversos conceitos e a diferentes formas de pensar e ver o mundo, todas mantendo como fio condutor o protagonismo das personas envolvidas no processo.

Além disso, trata-se de uma prática que se constrói horizontalmente, no cotidiano da escola, numa perspectiva multidisciplinar, contextualizada, fundamentada em questões de interesse dos sujeitos praticantes. Estrutura-se e se solidifica a partir da interação e contribuição de todos os envolvidos, na perspectiva de uma teia de conhecimentos que se intercruzam possibilitando a autoria em atividades divertidas e criativas.

Construída a partir de uma história imagética, com uma sintaxe e semântica utilizadas para reforçar as ideias que pretende representar, essa estratégia se volta para um público que ainda não se apropriou da escrita, mas que, por outro lado, consegue fazer uma leitura plena não só do mundo físico em que vive, mas também do universo informacional a que tem acesso através do toque de um dedo. Volta-se, portanto, para o que se conhece como leitor ubíquo (SANTAELLA, 2010).

Nessa perspectiva da ubiquidade, a estratégia se ressignifica, ultrapassando o espaço das imagens e palavras registradas no papel e penetrando no universo das tecnologias digitais que compõem o cotidiano dos sujeitos que vivenciam essa prática, multiplicando as possibilidades de interpretação.

\section{Referências Bibliográficas}

ALVES, Nilda. Praticantepensante de cotidianos/organização e introdução Alexandra Garcia, Inês Barbosa de Oliveira; textos selecionados de Nilda Alves. $1^{\text {a }}$ ed. Belo Horizonte: Autêntica Editora, 2015.

FERREIRO, Emília; TEBEROSKY, Ana; LICHTENSTEIN, Diana Myriam. Psicogênese da língua escrita. Artes Médicas, 1986.

FREIRE, Paulo. Educação como prática da liberdade. Editora Paz e Terra, 1967.

SANTAELLA, Lucia. A Ecologia Pluralista da Comunicação. Conectividade, mobilidade, ubiquidade. São Paulo: Paulus, 2010.

SERRES, Michel. Polegarzinha. Bertrand Brasil, 2013.

SOARES, Magda. Alfabetização e letramento: caderno do professor. Magda Becker Soares; Antônio Gomes Batista (Literacy-alfabetização and literacy-letramento: Teacher notebook/Magda Becker Soares; Antônio Gomes Batista) (p. 64). Belo Horizonte: Ceale/FaE/UFMG, 2005.

SOARES, Magda. Letramento e alfabetização: as muitas facetas. 2000. 


\section{Contato dos autores}

Cristina Ferreira Branco | cristina.branco.cp2@gmail.com

Gilsely de Carvalho G. do Nascimento | gilselynascimento@gmail.com

Renatho Siqueira |rsilva@unicarioca.edu.br

André Cotelli E. Santo | asanto@unicarioca.edu.br 